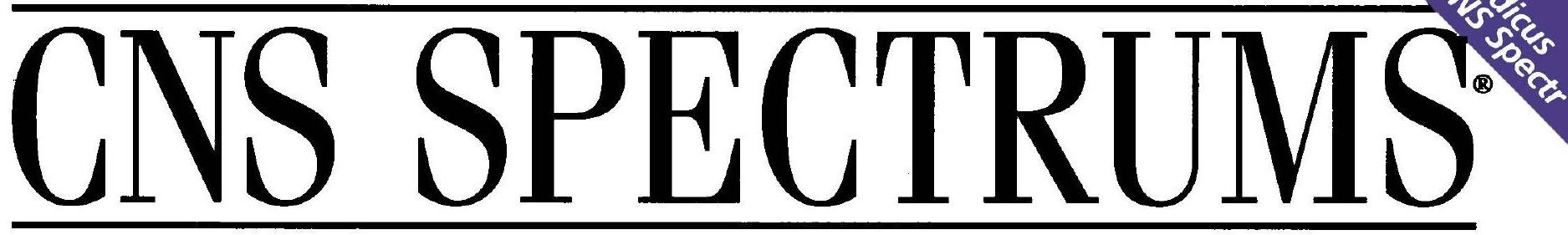

The International Journal of Neuropsychiatric Medicine

\title{
9
}

\section{Posttraumatic Stress Disorder}

Guest Editor-Arieh Y. Shalev, MD

INTRODUCTION

The Interdisciplinary Study of Posttraumatic Stress Disorder A.Y. Shalev

ORIGINAL RESEARCH

Amnesia for Traumatic Events Among Recent Survivors: A Pilot Study

Y. Yovell, Y. Bannett, and A.Y. Shalev

\section{REVIEW ARTICLES}

Brain-Imaging Studies of Posttraumatic Stress Disorder

I. Liberzon and K.L. Pban

The Neuroendocrinology of

Posttraumatic Stress Disorder: New Directions

A.M. Rasmusson, M. Vythilingam, and C.A. Morgan III

Acute Stress Reactions:

Can Biological Responses Predict Posttraumatic Stress Disorder?

$$
\text { R.A. Bryant }
$$

Contemporary Longitudinal Methods

for the Study of Trauma and

Posttraumatic Stress Disorder

L.A. King, D.W. King,

D.M. Salgado, and A.Y. Shalev

Genetics of Posttraumatic

Stress Disorder

R.H. Segman and A.Y. Shalev

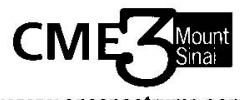

www.cnsspectrums.com

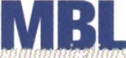

CNS Spectrums is an Index Medicus journal. 


\section{Time for wakefulness}

PROVIGIL ${ }^{\circledR}$ (modafinil) TABLETS

BRIEF SUMMARY: Consult Package Insert for Complete Prescribing Information

INDICATIONS and USAGE: To improve wakefulness in patients with excessive daytime sleepiness associated with narcolepsy.

CONTRAINDICATIONS: Known hypersensitivity to PROVIGIL

PRECAUTIONS: General: Patients should be cautioned about operating an automobile or other hazardous machinery until they are reasonably certain that PROVIGIL therapy will not adversely affect their ability to engage in such activities.

Cardiovascular System: In clinical studies of PROVIGIL, signs and symptoms including chest pain palpitations, dyspnea, and transient ischemic T-wave changes on ECG were observed in 3 subjects in association with mitral valve prolapse or left ventricular hypertrophy. It is recommended that PROVIGIL tablets not be used in patients with a history of left ventricular hypertrophy or ischemic ECG changes, chest pain, arrhythmia or other clinically significant manifestations of mitral valve prolapse in association with CNS stimulant use. Patients with a recent history of Ml or unstable angina should be treated with caution. Periodic monitoring of hypertensive patients taking PROVIGIL may be appropriate.

Central Nervous System: Caution should be exercised when PROVIGIL is given to patients with a history of psychosis. Patients with Severe Renal Impairment: Treatment with PROVIGIL resulted in much higher exposure to its inactive metabolite, modafinil acid, but not PROVIGIL itself.

Patients with Severe Hepatic Impairment: PROVIGIL should be administered at a reduced dose because its clearance is decreased.

Patients Using Contraceptives: The effectiveness of steroidal contraceptives may be reduced when used with PROVIGIL and for 1 month after discontinuation. Alternative or concomitant methods of contraception are recommended during and for 1 month after treatment.

Information for Patients: Physicians are advised to discuss the following with patients taking PROVIGIL: Pregnancy: Animal studies to assess the effects of PROVIGIL on reproduction and the developing fetus were not conducted so as to ensure a comprehensive evaluation of the potential of PROVIGIL to adversely affect fertility, or cause embryolethality or teratogenicity. Patients should notity their physician if they become pregnant or intend to become pregnant during therapy. They should be cautioned of the potential increased risk of pregnancy when using steroidal contraceptives (including depot or implantable contraceptives) with PROVIGIL and for 1 month after discontinuation. Nursing: Patients should notify their physician if they are breast feeding. Concomitant Medication: Patients should inform their physician if they are taking or plan to take any prescription or over-the-counter drugs, because of the potential for drug interactions. Alcohol: It is prudent to avoid alcohol while taking PROVIGIL. Allergic Reactions: Patients should notity their physician if they develop a rash, hives, or a related allergic phenomenon.

Drug Interactions: CNS Active Drugs: In a single-dose study, coadministration of PROVIGIL $200 \mathrm{mg}$ with methyiphenidate $40 \mathrm{mg}$ delayed the absorption of PROVIGIL by approximately 1 hour. The coadministration of a single dose of clomipramine $50 \mathrm{mg}$ with PROVIGIL $200 \mathrm{mg} /$ day did not affect the pharmacokinetics of either drug. One incident of increased levels of clomipramine and its active metabolite desmethylclomipramine has been reported. In single-dose study with PROVIGIL (50,100 or $200 \mathrm{mg}$ ) and triazolam $0.25 \mathrm{mg}$, no clinically important alterations in the safety profile of either drug were noted. In the absence of interaction studies with monoamine oxidase (MAO) inhibitors, caution should be exercised Potential Interactions with Drugs That Inhibit, Induce, or Are Metabolized by Cytochrome P-450 Isoenzymes and Othe Hepatic Enzymes: Chronic dosing of PROVIGIL $400 \mathrm{mg} / \mathrm{da}$ resulted in $\sim 20 \%$ mean decrease in PROVIGIL plasma trough concentration suggesting that PROVIGIL may have caused induction of its metabolism. Coadministration of potent inducers of CYP3A4

(eg, carbamazepine, phenobarbital, rifampin) or inhibitors of CYP3A4 (eg, ketoconazole, itraconazole) could alter the levels of PROVIGIL. Caution needs to be exercised when PROVIGIL is coadministered with drugs that depend on hepatic enzymes for their clearance; some dosage adjustment may be required. Potentially relevant in vivo effects of PROVIGIL based on in vitro data are:

A slight induction of CYP1A2 and CYP2B6 in a concentration-dependent manner has been observed. A modest induction of CYP3A4 in a concentration-dependent manner may result in lower levels of CYP3A4 substrates (eg, cyclosporine, steroidal contraceptives, theophylline).

An apparent concentration-related suppression of expression of CYP2C9 activity may result in higher levels of CYP2C9 substrates (eg, warfarin, phenytoin).

A reversible inhibition of CYP2C19 may result in higher levels of CYP2C19 substrates (eg, diazepam, propranolol, phenytoin, S-mephenytoin)

In some patients deficient in CYP2D6, the amount of metabolism via CYP2C19 may be substantially larger Co-therapy with PROVIGIL may increase levels of some tricyclic antidepressants (eg, clomipramine, desipramine)

\section{Carcinogenesis, Mutagenesis, Impairment of Fertility}

Carcinogenesis: The highest dose studied in carcinogenesis studies represents 1.5 times (mouse) or 3 times (rat) the maximum recommended human daily dose of $200 \mathrm{mg}$ on a $\mathrm{mg} / \mathrm{m}^{2}$ basis. There was no evidence of tumorigenesis associated with PROVIGIL administration in these studies, but because the mouse study used an inadequate high dose below that representative of a maximum tolerated dose, the carcinogenic potential in that species has not been fully evaluated. Mutagenesis: There was no evidence of mutagenic or clastogenic potential of PROVIGIL. Impairment of Fertility: When PROVIGIL was administered orally to male and female rats prior to and throughout mating and gestation at up to $100 \mathrm{mg} / \mathrm{kg} / \mathrm{day}$ ( 4.8 times the maximum recommended daily dose of $200 \mathrm{mg}$ on a mg/m² basis) no effects on fertility were seen. This study did not use sufficiently high doses or large enough sample size to adequately assess effects on fertility.

Pregnancy: Pregnancy Category C: Embryotoxicity was observed in the absence of maternal toxicity when rats received oral PROVIGIL throughout the period of organogenesis. At $200 \mathrm{mg} / \mathrm{kg} / \mathrm{day}$ ( 10 times the maximum recommended daily human dose of $200 \mathrm{mg}$ on a mg/m² basis) there was an increase in resorption, hydronephrosis, and skeletal variations. The no-effect dose for these effects was $100 \mathrm{mg} / \mathrm{kg} /$ day ( 5 times the maximum recommended daily human dose on a $\mathrm{mg} / \mathrm{m}^{2}$ basis). When rabbits received ora PROVIGIL throughout organogenesis at doses up to $100 \mathrm{mg} / \mathrm{kg} /$ day (10 times the maximum recommended daily human dose on a $\mathrm{mg} / \mathrm{m}^{2}$ basis), no embryotoxicity was seen. Neither of these studies, however, used optimal doses for the evaluation of embryotoxicity. Although a threshold dose for embryotoxicity has been identified, the full spectrum of potential toxic effects on the fetus has not been characterized. When rats were dosed throughout gestation and lactation at doses up to $200 \mathrm{mg} / \mathrm{kg} /$ day, no developmental toxicity was noted post-natally in the offspring. There are no adequate and well-controlled trials with PROVIGIL in pregnant women. PROVIGIL should be used during pregnancy only if the potential benefit outweighs the potential risk.
Labor and Delivery: The effect of PROVIGIL on labor and delivery in humans has not been systematically investigated. Seven normal births occurred in patients who had received PROVIGIL during pregnancy. Nursing Mothers: It is not known whether PROVIGIL or its metabolite are excreted in human milk. Caution should be exercised when PROVIGIL is administered to a nursing woman.

PEDIATRIC USE: Safely and effectiveness in individuals below 16 years of age have not been established. GERIATRIC USE: Safety and effectiveness in individuals above 65 years of age have not been established. ADVERSE REACTIONS: PROVIGIL has been evaluated for safety in over 2200 subjects, of whom more than 900 subjects with narcolepsy or narcolepsy/hypersomnia were given at least 1 dose of PROVIGIL. In controlled clinical trials, PROVIGIL was well tolerated, and most adverse experiences were mild to moderate. The most commonly observed adverse events ( $\geq 5 \%$ ) associated with the use of PROVIGIL more frequently than placebo-treated patients in controlled US and foreign studies were headache, infection, nausea, nervousness, anxiety, and insomnia In US controlled trials, $5 \%$ of the 369 patients who received PROVIGII discontinued due to an adverse experience. The most frequent $(\geq 1 \%)$ reasons for discontinuation that occurred at a higher rate for PROVIGIL than placebo patients were headache $(1 \%)$, nausea $(1 \%)$, depression $(1 \%)$ and nervousness $(1 \%)$. The incidence of adverse experiences that occurred in narcolepsy patients at a rate of $\geq 1 \%$ and were more frequent in patients treated with PROVIGIL than in placebo patients in US controlled trials are listed below. Consult full prescribing information on adverse events.

Body as a whole: Headache,' chest pain, neck pain, chills, rigid neck, fever/chills

Digestive: Nausea,' diarrhea, ${ }_{1}^{1}$ dry mouth,' anorexia,' abnormal liver function,', vomiting, mouth ulcer, gingivitis, thirst Respiratory system: Rhinitis, pharyngitis,' lung disorder, dyspnea, asthma, epistaxis

Nervous system: Nervousness,' dizziness, depression, anxiety, cataplexy, insomnia, paresthesia

dyskinesia, ${ }^{3}$ hypertonia, confusion, amnesia, emotional lability, ataxia, tremor

Cardiovascular: Hypotension, hypertension, vasodilation, arrhythmia, syncope

Hemic/Lymphatic: Eosinophilia

Special senses: Amblyopia, abnormal vision

Metabolic/Nutritional: Hyperglycemia, albuminuria

Musculo-skeletal: Joint disorder

Skin/Appendages: Herpes simplex, dry skin

Urogenital: Abnormal urine, urinary retention, abnormal ejaculation

IIncidence $\geq 5 \%,{ }^{2}$ Elevated liver enzymes ${ }^{3}$ Oro-facial dyskinesias, ${ }^{4}$ Incidence adjusted for gender.

Dose Dependency: In US trials, the only adverse experience more frequent ( $\geq 5 \%$ difference) with PROVIGIL $400 \mathrm{mg} /$ day than PROVIGIL $200 \mathrm{mg} /$ day and placebo was headache.

Vital Signs Changes: There were no consistent effects or patterns of change in vital signs for patients treated with PROVIGIL in the US trials.

Weight Changes: There were no clinically significant differences in body weight change in patients treated with PROVIGIL compared to placebo.

Laboratory Changes: Mean plasma levels of gamma-glutamyl transferase (GGT) were higher following administration of PROVIGIL but not placebo. Few subjects (1\%) had GGT elevations outside the normal range. Shitt to higher, but not clinically significantly abnormal, GGT values appeared to increase with time on PROVIGIL. No differences were apparent in alkaline phosphatase, alanine aminotransferase, aspartate aminotransferase total protein, albumin, or total bilirubin. There were more elevated eosinophil counts with PROVIGIL than placebo in US studies; the eosinophil counts with PROVIGIL than p
differences were not clinically significant.

ECG Changes: No treatment-emergent pattern of ECG abnormalities was found in US studies following administration of PROVIGIL. Postmarketing Reports

In addition to the adverse events observed during clinical trials, the

Tablets following adverse events have been identified during post-approval use of PROVIGIL in clinical practice. Because these adverse events are reported voluntarily from a population of uncertain size, reliable estimates of their frequency cannot be made.

Hematologic: Agranulocytosis

Central Nervous System: Symptoms of psychosis, symptoms of mania

DRUG ABUSE and DEPENDENCE: Abuse Potential and Dependence: In addition to wakefulness-promoting effect and increased locomotor activity in animals, in humans, PROVIGIL produces psychoactive and euphoric effects, alterations in mood, perception, thinking, and feelings typical of other CNS stimulants. In vitro, PROVIGIL binds to the dopamine reuptake site and causes an increase in extracellular dopamine but no increase in dopamine release. PROVIGIL is reinforcing, as evidenced by its self-administration in monkeys previously trained to self-administer cocaine. In some studies PROVIGIL was also partially discriminated as stimulant-like. Physicians should follow patients closely, especially those with a history of drug and/or stimulant (eg, methylphenidate, amphetamine, or cocaine) abuse. Patients should be observed for signs of misuse or abuse (eg, incrementation of doses or drug-seeking behavior). In individuals experienced with drugs of abuse, PROVIGIL produced psychoactive and euphoric effects and feelings consistent with other scheduled CNS stimulants (methylphenidate). Patients should be observed for signs of misuse or abuse.

Withdrawal: Following 9 weeks of PROVIGIL use in 1 US trial, no specific symptoms of withdrawal were observed during 14 days of observation, although sleepiness returned in narcoleptic patients.

OVERDOSAGE: Human Experience: A total of 151 doses of $\geq 1000 \mathrm{mg} /$ day $(5$ times the maximum recommended daily dose) have been recorded for 32 individuals. Doses of $4500 \mathrm{mg}$ and $4000 \mathrm{mg}$ were taken intentionally by 2 patients participating in foreign depression studies. In both cases, adverse experiences observed were limited, expected, and not life-threatening, and patients recovered fully by the following day. The adverse experiences included excitation or agitation, insomnia, and slight or moderate elevations in hemodynamic parameters. In neither of these cases nor in others with doses $\geq 1000 \mathrm{mg} / \mathrm{day}$, including experience with up to 21 consecutive days of dosing at $1200 \mathrm{mg} /$ day, were any unexpected effects or specific organ toxicities observed. Other observed high-dose effects in clinical studies have included anxiety, irritability, aggressiveness, confusion, nervousness, tremor, palpitations, sleep disturbances, nausea diarrhea, and decreased prothrombin time. Overdose Management: No specific antidote to the toxic effects of PROVIGIL overdose has been identified. Overdoses should be managed with primarily supportive care, including cardiovascular monitoring. Emesis or gastric lavage should be considered. There are no data suggesting that dialysis or urinary acidification or alkalinization enhance drug elimination. The physician should consider contacting a poison-control center on the treatment of any overdose.

Manufactured for: Cephalon, Inc., West Chester, PA 19380

For more information about PROVIGIL, please call Cephalon Professional Services at 1-800-896-5855 or visit our Website at wWw.PROVIGIL.com.

【C Cephalon - (c) 2003 Cephalon, Inc. PR0338 Feb 2003 All rights reserved. Printed in USA. 


\section{Introduction}

CNS Spectrums is an Index Medicus journal that publishes original scientific literature and reviews on a wide variety of neuroscientific topics of interest to the clinician on a monthly basis. Our mission is to provide physicians with an editorial package that will enhance and increase their understanding of neuropsychiatry; therefore, manuscripts that address crossover issues between neurology and psychiatry will be given immediate priority.

\section{Scope of Manuscripts}

CNS Spectrums will consider and encourages the following types of articles for publication:

Original Research presents methodologically sound original data.

Reviews are comprehensive articles summarizing and synthesizing the literature on various neuropsychiatric topics and presented in a scholarly and clinically relevant fashion. Diagnostic and treatment algorithms should be designed to aid the clinician in diagnosis and treatment.

Single or multiple Case Reports will be considered and are encouraged for publication.

Letters to the Editor will be considered and are encouraged for publication. All letters will be edited for style, clarity, and length.

\section{Manuscript Submission}

General Information Two copies of the manuscript with a letter on the author's letterhead should be submitted to Jack M. Gorman, MD, Editor (or, in Europe, to Joseph Zohar, MD, International Editor), c/o MBL Communications, 333 Hudson Street, 7th Floor, New York, NY 10013. Authors are also required to submit their manuscripts on computer disk in Microsoft Word format. Disks should be labeled with the word processing program, title of paper, and lead author's name. Accepted manuscripts will be edited for clarity and style.

Letters of Permission to Reproduce Previously Published Material All material reproduced from previously published copyrighted material must be accompanied by a letter of permission from the copyright holder. All such material should include a full credit line (eg, in the figure or table legend) acknowledging the original source. Any citation of unpublished material or personal communication should also be accompanied by a letter of permission for anyone who is not an author of the paper.

Peer Review Authors must provide three to five names of qualified potential reviewers with no conflict of interest in reviewing the work. Contact information with affiliations and e-mail address should be included. Peer review is anonymous.

\section{Manuscript Preparation}

Length Reviews and Original Research should not exceed 5,000 words (excluding References). Diagnostic and treatment algorrithms should contain an introduction, flowcharts or a series of graphs, and a concise summary. Letters should not exceed 1,500 words. Single Case Reports should not exceed 3,750 words and may be submitted with a photograph, if applicable.

Please note: If your article is Original Research, it should he formatted as: Abstract (100-200 words); Introduction; Methods; Findings; Discussion; Conclusion; References (numbered and comprehensive list).

Spacing and Pagination One space should be left after commas and periods. Manuscripts should be double-spaced and numbered.

Abstract Authors must provide a brief abstract of 100-200 words.

Focus Points Please provide three to six points that dictate the main focus of the manuscript and clearly illustrates what you are trying to convey in the article.

Figures/Tables Please provide figures and/or tables if content is amenable to it.

References Please use American Medical Association style. References should be superscripted in text, then numbered, and comprehensive in list. See the following examples:

1. Jones J. Necrotizing Candida esophagitis. JAMA. $1980 ; 244: 2190-2191$.

2. Stryer L. Biochemistry. 2nd ed. San Francisco, Callif: WH Freeman Co; 1980:559-596.

Continuing Medical Education Authors must submit six multiplechoice questions (three Type $A$ and three Type K), with answers.

Copyright Materials are accepted for exclusive publication in CNS Spectrums and become the property of CNS Spectrums. Permission to reproduce material must be obtained from the publisher.

\section{Disclosure of Commercial and Non-Commercial Interests}

Authors must include a statement about all forms of support, including grant and pharmaceutical support, affiliations, and, honoraria, received for past and present material. Such information may, at the editor's discretion, he shared with reviewers. If the article is accepted for publication, the editors will consult with the authors as to whether this information should be included in the published paper.

\section{Submission Checklist}

$\square$ Original manuscript plus one copy, with cover letter on author's letterhead

$\square$ Copies of permission letters to reproduce previously published and unpublished material

$\square$ A brief abstract of the article

$\square$ Six CME multiple-choice questions with answers

$\square$ Three to six focus points

$\square$ Disk labeled with the word processing program, title of paper, and lead author's name

$\square$ Names and affiliations of three to five potential peer reviewers 


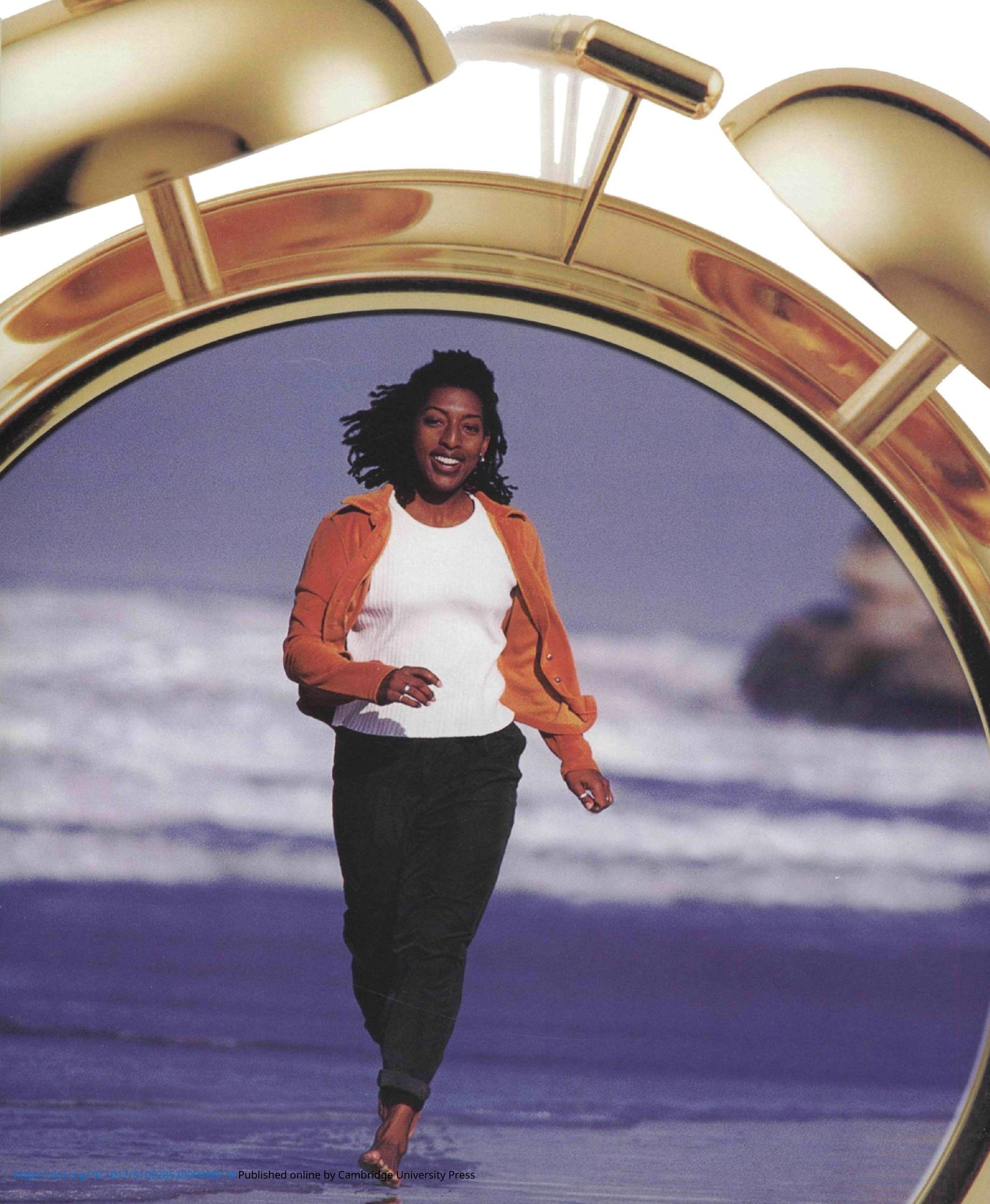




\section{Time for wakefulness}

\section{A unique wake-promoting agent}

PROVIGIL promotes daytime wakefulness, improving patients' ability to participate in daily activities-with no effect on nighttime sleep.$^{1-3}$

\section{Long-term safety}

The long-term safety profile of PROVIGIL has been demonstrated for up to 136 weeks. ${ }^{4}$

PROVIGIL was generally well tolerated. Most frequently reported adverse events in clinical trials were headache, nausea, nervousness, anxiety, infection, and insomnia. Most adverse events were mild to moderate. PROVIGIL may interact with drugs that inhibit, induce, or are metabolized by cytochrome P450 isoenzymes.

\section{Dosing}

Recommended dose for PROVIGIL is $200 \mathrm{mg}$ taken orally once daily in the morning. Both PROVIGIL doses, $200 \mathrm{mg}$ and $400 \mathrm{mg}$ QD, were effective.

PROVIGIL is indicated to improve wakefulness in patients with excessive daytime sleepiness associated with narcolepsy.

References: 1. PROVIGIL full prescribing information. 2. US Modafinil in Narcolepsy Multicenter Study Group. Randomized trial of modafinil for the treatment of pathological somnolence in narcolepsy. Ann Neurol. 1998;43:88-97. 3. US Modafinil in Narcolepsy Multicenter Study Group. Randomized trial of modafinil as a treatment for the excessive daytime somnolence of narcolepsy. Neurology. 2000;54:1166-1175. 4. Data on file, Cephalon, Inc.

\section{PROVIGIL (MODAFINILIC \\ Tablets \\ Wake up to life..$^{\text {TM }}$}

Please see brief summary of prescribing information on adjacent page.

For more information, call 1-800-896-5855 or visit our Website at www.PROVIGIL.com. 


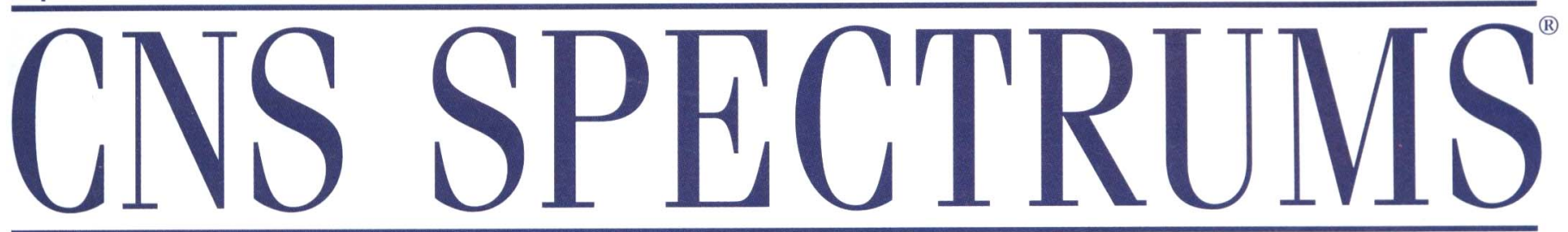

The International Journal of Neuropsychiatric Medicine

EDITOR

Jack M. Gorman, MD

Mount Sinai School of Medicine

New York, NY

\section{ASSOCIATE AND FOUNDING EDITOR}

Eric Hollander, MD

Mount Sinai School of Medicine

New York, NY

INTERNATIONAL EDITOR

Joseph Zohar, MD

Chaim Sheba Medical Center

Tel-Hashomer, Israel

\section{ASSOCIATE INTERNATIONAL EDITORS \\ EUROPE}

Donatella Marazziti, MD

University of Pisa

Pisa, Italy

\section{MID-ATLANTIC}

Dan J. Stein, MD, PhD

University of Stellenbosch

Tygerberg, South Africa

\section{FAR EAST}

Shigeto Yamawaki, MD, PhD

Hiroshima University School

of Medicine

Hiroshima, Japan

\section{CONTRIBUTING WRITERS}

Richard A. Bryant, $\mathrm{PhD}$

Lynda A. King, PhD

Israel Liberzon, MD

Ann M. Rasmusson, MD

Ronnen H. Segman, MD

Arieh Y. Shalev, MD

Yoram Yovell, MD, PhD

\section{BOARD OF ADVISORS}

NEUROLOGISTS

Mitchell F. Brin, MD

University of California, Irvine

Irvine, CA

Jeffrey L. Cummings, MD

University of California, Los Angeles Los Angeles, CA

Jerome Engel, Jr., MD, PhD

University of California, Los Angeles

Los Angeles, CA

Mark S. George, MD

Medical University of South Carolina

Charleston, SC

Richard B. Lipton, MD

Albert Einstein College of Medicine Bronx, NY

C. Warren Olanow, MD, FRCPC

Mount Sinai School of Medicine

New York, NY

Steven George Pavlakis, MD

Maimonides Medical Center

Brooklyn, NY

Stephen D. Silberstein, MD, FACP

Thomas Jefferson University

Philadelphia, PA

Michael Trimble, MD, FRCP, FRPsych National Hospital for Neurology and Neurosurgery

London, United Kingdom

\section{PSYCHIATRISTS}

Margaret Altemus, MD

Cornell University Medical College New York, NY

Dennis S. Charney, MD

National Institute of Mental Health

Bethesda, MD

Dwight L. Evans, MD

University of Pennsylvania

Philadelphia, PA

Siegfried Kasper, MD

University of Vienna

Vienna, Austria

Martin B. Keller, MD

Brown Medical School

Providence, RI

Lorrin M. Koran, MD

Stanford University School of Medicine

Stanford, CA

Yves Lecrubier, MD

Hôpital de la Salpêtrière

Paris, France

Herbert Y. Meltzer, MD

Vanderbilt University Medical Center

Nashville, TN

Stuart A. Montgomery, MD

St. Mary's Hospital Medical School

London, United Kingdom

Charles B. Nemeroff, MD, PhD

Emory University School of Medicine Atlanta, GA

Humberto Nicolini, MD, PhD

National Mexican Institute of Psychiatry Mexico City, Mexico

Stefano Pallanti, MD, PhD

University of Florence

Florence, Italy

Katharine Phillips, MD

Brown Medical School

Providence, RI

Harold A. Pincus, MD

Western Psychiatric Institute \& Clinic

RAND-University of Pittsburgh Health Institute, Pittsburgh, PA

Scott L. Rauch, MD

Massachusetts General Hospital

Charlestown, MA

Alan F. Schatzberg, MD

Stanford University School of Medicine

Stanford, CA

Stephen M. Stahl, MD, PhD

University of California, San Diego

La Jolla, California

Norman Sussman, MD, DFAPA

New York University Medical School

New York, NY

Karen Dineen Wagner, MD, PhD

The University of Texas Medical Branch Galveston, Texas

Herman G.M. Westenberg, MD

University Hospital Utrecht

Utrecht, The Netherlands

Stuart C. Yudofsky, MD

Baylor College of Medicine Houston TX

MBL COMMUNICATIONS Corporate Staff

CEO \& PUBLISHER

Darren L. Brodeur

ASSOCIATE PUBLISHER

Elizabeth Katz

MANAGING EDITOR

Christopher Naccari

SENIOR EDITOR

Deborah Hughes

DEPUTY SENIOR EDITOR

José R. Ralat

ACQUISITIONS EDITOR

Lisa Arrington

ASSISTANT ACQUISITIONS EDITOR
Eileen S. Seligman
COPY EDITOR
Keith Papa
EDITORIAL ASSISTANT
Shelley Wong
PRODUCTION MANAGER
Lila Moses
GRAPHIC DESIGNER
Anthony J. Korsak
CONTROLLER
John Spano

\section{NATIONAL ACCOUNT MANAGER \\ Kelly J. Staley \\ CME PROJECTS DIRECTOR \\ Chris Van Denburg \\ OFFICE MANAGER \\ Claudette Crawford \\ OFFICE ASSISTANT \\ Manuel Pavón \\ INFORMATION TECHNOLOGY \\ Adam Bolt \\ CORPORATION COUNSEL \\ Lawrence Ross, Esq \\ Bressler, Amery, and Ross}

CNS Spectrums' editorial mission is to address relevant neuropsychiatric topics, including the prevalence of comorbid diseases among patients, and original research and reports that emphasize the profound diagnostic and physiologic connections made within the neurologic and psychiatric fields. The journal's goal is to serve as a resource to psychiatrists and neurologists seeking to understand and treat disturbances of cognition, emotion, and behavior as a direct consequence of central nervous system disease, illness, or trauma. 


\section{Vivactil (Protriptyline HCl, USP) 5-mg and 10-mg Tablets}

Briel Summary: See package insert tor tull prescribing intormation

INOICATIONS AND USAGE: Protriptyline hydrochloride tablets are indicated for the treatment of symptoms mental depression in patients who are under close medical supervision. Its activating properties make it particularly suitable for withdrawn and anergic patients.

CONTRAIMOICATLONS: Protriptyline hydrochloride tablets are contraindicated in patients who have shown prior hypersensitivity to it.

It should not be given concomitantly with a monoamine oxidase inhibiting compound. Hyperpyretic crises, severe convulsions, and deaths have occurred in patients receiving tricyclic antidepressant and monoamine oxidase inhibiting drug simultaneously. When it is desired to substitute protriptyline for a monoamine oxidase inhibitor, a minimum of 14 days should be allowed to elapse after the latter is discontinued. Protriptyline should then be initiated should be allowed to elapse after the latter is discontinued. Protrip with gradual increase in dosage until optimum response is achieved.

Protriptyline is contraindicated in patients taking cisapride because of the possibility of adverse cardiac interactions inclu ing prolongation of the QT interval, cardiac arrhythmias and conduction system disturbances.

This drug should not be used during the acute recovery phase following myocardial infarction.

WARHINGS: Protriptyline may block the antihypertensive effect of guanethidine or similarly acting compounds.

Protriptyline should be used with caution in patients with a history of seizures, and, because of its autonomic activity in patients with a tendency to urinary retention, or increased intraocular tension.

Tachycardia and postural hypotension may occur more frequently with protriptyline than with other antidepressant drugs Protriptyline should be used with caution in elderly patients and patients with cardiovascular disorders; such patients should be observed closely because of the tendency of the drug to produce tachycardia, hypotension, arrhythmias, and prolongation of the conduction time. Myocardial infarction and stroke have occurred with drugs of this class.

On rare occasions, hyperthyroid patients or those receiving thyroid medication may develop arrhythmias when this drug is given.

In patients who may use alcohol excessively, it should be borne in mind that the potentiation may increase the dange inherent in any suicide attempt or overdosage.

Podiatric Use: The safety and effectiveness of protriptyline in pediatric patients have not been established.

Usage in Pregnancy: Safe use in pregnancy and lactation has not been established; therefore, use in pregnant women nursing mothers or women who may become pregnant requires that possible benefits be weighed against possible haz ards to mother and child.

In mice, rats, and rabbits, doses about ten times greater than the recommended human doses had no apparent adverse effects on reproduction.

PRECAUTIONS: General - When protriptyline $\mathrm{HCl}$ is used to treat the depressive component of schizophrenia psychotic symptoms may be aggravated. Likewise, in manic-depressive psychosis, depressed patients may experience a shift toward the manic phase if they are treated with an antidepressant drug. Paranoid delusions, with or without associated hostility, may be exaggerated. In any of these circumstances, it may be advisable to reduce the dose of protriptyline or to use a major tranquilizing drug concurrently.

Symptoms, such as anxiety or agitation, may be aggravated in overactive or agitated patients.
Sheposs

The possibility of suicide in depressed patients remains during treatment and until significant remission occurs. This type of patient should not have access to large quantities of the drug

Concurrent administration of protriptyline and electroshock therapy may increase the hazards of therapy. Such treatment should be limited to patients for whom it is essential.

Discontinue the drug several days before elective surgery, if possible.

Both elevation and lowering of blood sugar levels have been reported.

Intormatlon for Patlents: While on therapy with protriptyline, patients should be advised as to the possible impairment of mental and/or physical abilities required for performance of hazardous tasks, such as operating machinery or driving a motor vehicle.

Drug Interactlons: When protriptyline is given with anticholinergic agents or sympathomimetic drugs, including epinephrine combined with local anesthetics, close supervision and careful adjustment of dosages are required.

Hyperpyrexia has been reported when tricyclic antidepressants are administered with anticholinergic agents or with neuroleptic drugs, particularly during hot weather. Cimetidine is reported to reduce hepatic metabolism of certain tricyclic antidepressants, thereby delaying elimination and increasing steady-state concentrations of sants, thereby delaying elimination and increasing steady-state concentrations of
these drugs. Clinically significant effects have been reported with the tricyclic antidethese drugs. Clinicaily significant effects have been reported with the tricyclic antidepressants when used concomitantly with cimetidine. Increases in plasma levels of tri-

cychic antidepressants, and in the frequency and severty of side-efrects, particularly anticholnergic, have been reported when cimetialne was added to the drug regimen. Disconinuation of cimetidine in well-controlled patients receiving tricyclic antidepressants and cimetidine may decrease the plasma levels and efficacy of the antidepressants.

Tricyclic antidepressants may enhance the seizure risk in patients taking ULTRAM (tramadol hydrochloride). Protriptyline may enhance the response to alcohol and the effects of barbiturates and other CNS depressants.

Drups Metabolized by Cytochrome P450 206: The biochemical activity of the drug metabolizing isozyme cytochrome P450 2D6 (debrisoquine hydroxylase) is reduced in a subset of the Caucasian population (about $7 \%$ to $10 \%$ of Caucasians are so called "poor metabolizers"); reliable estimates of the prevalence of reduced P450 2D6 isozyme activity among Asian, African, and other populations are not yet available. Poor metabolizers have higher than expected plasma concentrations of tricyclic antidepressants (TCAs) when given usual doses. Depending on the fraction of drug metabolized by $P 4502 D 6$, the increase in plasma concentration may be small or quite large $(8$ fold increas tion of drug metabolized by

In addition, certain drugs inhibit the activity of this isozyme and make normal metabolizers resemble poor metabolizers. An individual who is stable on a given dose of TCA may become abruptly toxic when given one of these inhibiting drugs as concomitant therapy. The drugs that inhibit cytochrome P450 206 include some that are not metabolized by the enzyme (quinidine; cimetidine) and many that are substrates for $P 450206$ (many other antidepressants, phenothiazines, and the Type $1 C$ anti-arrhythmics, propafenone and flecainide). While all the selecti serotonin reuptake inhibitors (SSRis), e.g., fluoxetine, sertraline, and paroxetine, inhibit P450 206, they may vary in the extent of inhibition. The extent to which SSRI-TCA interactions may pose clinical problems will depend on th degree of inhibition and the pharmacokinetics of the SSRI involved. Nevertheless, caution is indicated in the coadministration of TCAs with any of the SSRIs and also in switching from one class to the other. Of particular importance, sufficient time must elapse before initiating TCA treatment in a patient being withdrawn from fluoxetine, given the long half-life of the parent and active metabolite (at least 5 weeks may be necessary).

Concomitant use of tricyclic antidepressants with drugs that can inhibit cytochrome P450 206 may require lower doses than usually prescribed for either the tricyclic anti-depressant or the other drug. Furthermore, whenever one of these other drugs is withdrawn from co-therapy, an increased dose of tricyclic antidepressant may be required. II is desirable to monitor TCA plasma levels whenever a TCA is going to be coadministered with another drug known to be an inhibitor of P450206.

Podlatric Use: The safety and effectiveness of protriptyline in pediatric patients have not been established. Goriatric Use: Clinical studies of protriptyline did not include sufficient numbers of subjects aged 65 and over to Goriarric Use: Clinical studies of protriptyline did not include sufficient numbers of subjects aged 65 and over to fied differences in responses between the elderly and younger patients. In general, dose selection for an elderly patient should be cautious, usually starting at the low end of the dosing range, reflecting the greate frequency of decreased hepatic, renai, or cardiac function, and of concomitant disease or other drug therapy. (see frequency of decreased hepatic, renal, or cardiac function, and of concom
WARNINGS, DOSAGE AND ADMINISTRATION, and ADVERSE REACTIONS.)

WARNINGS, DOSAGE AND ADMINISTRATION, and ADVERSE REACTIONS.)
ADVERSE REACTIONS: Within each category the following adverse reactions are listed in order of decreasing severity. ADVERSE REACTIONS: Within each category the following adverse reactions are listed in order of decreasing severity.
Included in the listing are a few adverse reactions which have not been reported with this specific drug. However, the Included in the listing are a few adverse reactions which have not been reported with this specific drug. However, the
pharmacological similarities among the tricyclic antidepressant drugs require that each of the reactions be considered when protriptyline is administered. Protriptyline is more likely to aggravate agitation and anxiety and produce cardiovascular reactions such as tachycardia and hypotension.

Cardlovascular: Myocardial infarction; stroke; heart block; arrhythmias; hypotension, particularly orthostatic hypotension; hypertension; tachycardia; palpitation.

Paychiatrle: Confusional states (especially in the elderly) with hallucinations, disorientation, delusions, anxiety, Rolerences

1. Vivactil [package insert]. East Hanover, NJ:Odyssey Pharmaceuticals, Inc. 2000

restlessness, agitation; hypomania; exacerbation of psychosis; insomnia, panic, and nightmares.

Neurological: Seizures; incoordination; ataxia; tremors; peripheral neuropathy; numbness, tingling, and paresthesias of extremities; extrapyramidal symptoms; drowsiness; dizziness; weakness and tatigue; headache; syndrome of inappropriate $\mathrm{ADH}$ (antidiuretic hormone) secretion; tinnitus; alteration in EEG patterns.

Anticholinergle: Paralytic ileus; hyperpyrexia; urinary retention, delayed micturition, dilatation of the urinary tract; constipation; blurred vision, disturbance of accommodation, increased intraocular pressure, mydriasis; dry mouth and rarely associated sublingual adenitis.

Allergic: Drug tever; petechiae, skin rash, urticaria, itching, photosensitization (avoid excessive exposure to sunlight); edema (general, or of face and tongue).

Hematologic; Agranulocytosis; bone marrow depression; leukopenia; thrombocytopenia; purpura; eosinophilia.

Gastrointestinal: Nausea and vomiting; anorexia; epigastric distress; diarrhea; peculiar taste; stomatitis; abdominal cramps; black tongue.

Endocrine: Impotence, increased or decreased libido; gynecomastia in the male; breast enlargement and galactorrhea in the fermale; testicular swelling; elevation or depression of blood sugar levels.

Other: Jaundice (simulating obstructive); altered liver function; parotid swelling; alopecia; flushing; weight gain or loss: urinary frequency, nocturia; perspiration.

Withdrawal Symptoms: Though not indicative of addiction, abrupt cessation of treatment after prolonged therapy may produce nausea, headache, and malaise.

OVERDOSAGE:

Deaths may occur from overdosage with this class of drugs. Multiple drug ingestion (including alcohol) is common in deliberate tricyclic antidepressant overdose. As management of overdose is complex and changing, it is recommended that the physician contact a poison control center for current information on treatment. Signs and symptoms of toxicity develop rapidly after tricyclic antidepressant overdose, therefore, hospital monitoring is required as

MANIFESTATIONS:

Gritical manifestations of overdosage include: cardiac dysrhythmias, severe hypotension, convulsions, and CNS depression, Including coma. Changes in the electrocardiogram, particularly in QRS axis or width, are clinically significant indicators of tricyclic antidepressant toxicity.

Other signs of overdose may include: confusion, disturbed concentration, transient visual hallucinations, dilated pupils, gitation, hyperactive reflexes, stupor, drowsiness, muscle rigidity, vomiting, hypothermia, hyperpyrexia, or any of the symptoms listed under ADVERSE REACTIONS.

MANAGEMENT:

General:

Obtain an ECG and immediately initiate cardiac monitoring. Protect the patient's airway, establish an intravenous line and initiate gastric decontamination. A minimum of six hours of observation with cardiac monitoring and observation for signs of CNS or respiratory depression, hypotension, cardiac dysrhythmias and/or conduction blocks, and seizures is necessary. If signs of toxicity occur at any time during this period, extended monitorin is required. There are case reports of patients succumbing to fatal dysrhythmias late atter overdose. These patients had clinical evidence of significant poisoning prior to death and most received inadequate gastrointestinal decontamination Monitoring of plasma drug levels should not guide management of the patient.

Gastrointestinal Decontamination:

All patients suspected of a tricyclic antidepressant overdose should receive gastrointestinal decontamination. This should include large volume gastric lavage tollowed by activated charcoal. If consciousness is impaired, the airway should be secured prior to lavage. Emesis is contraindicated.

Cardiovascular:

A maximal limb-lead ORS duration of $\geq 0,10$ seconds may be the best indication of the severity of the overdose Intravenous sodium bicarbonate should be used to maintain the serum $\mathrm{pH}$ in the range of 7.45 to 7.55 . If the $\mathrm{pH}$ response is inadequate, hyperventilation may also be used Concomitant use of hyperventilation and sodium bicarbonate should be done with extreme caution, with frequent $\mathrm{pH}$ monitoring. $\mathrm{A} \mathrm{pH}>760$ or a pCO2 $<20 \mathrm{mmHg}$ is extreme castion, with undesirable. Dysrhythmias unresponsive to sodium bicarbonate therapy/hyperventilation generally contraindicated (e.g., quinidine, disopyramide, and procainamide).
In rare instances, hemopertusion may be beneficial in acute refractory cardiovascular instability in patients with acute toxicity. However, hemodialysis, peritoneal dialysis exchange transfusions, and forced diuresis generally have been reported as ineffective in exchange transfusions, and forced

CNS:

In patients with CNS depression, early intubation is advised because of the potential for abrupt deterioration. Seizures should be controlled with benzodiazepines or, if these are inefective, other anticonvulsants (e.g., phenobarbital, phenytoin). Physostigmine is not recommended except to treat life-threat ening symptoms that have been unresponsive to other therapies, and then only in close consultation with a poison contro PSYCHIATRIC FOLLOW-UP:

Since overdosage is often detiberate, patients may attempt suicide by other means during the recovery phase. sychiatric reterral may be appropriate.

PEDIATRIC MANAGEMENT:

The principles of management of child and adult overdosages are similar. It is strongly recommended that the physician contact the local poison control center for specitic pediatric treatment.

DOSAGE AND ADMINISTRATION:

Dosage should be in

Usual Adull Dosage - Fitteen to $40 \mathrm{mg}$ a day divided into 3 or 4 doses. If necessary, dosage may be increased to $60 \mathrm{~m}$ a day. Dosages above this amount are not recommended. Increases should be made in the morning dose.

Adolescent and Elderly Patients - In general, lower dosages are recommended for these patients. Five mg 3 times a da may be given initially, and increased gradually it necessary, in elderly patients, the cardiovascular system must be monitored closely if the daily dose exceeds $20 \mathrm{mg}$.

When satisfactory improvement has been reached, dosage should be reduced to the smallest amount that will maintain relief of symptoms.

Minor adverse reactions require reduction in dosage. Major adverse reactions or evidence of hypersensitivity require prompt discontinuation of the drug

The safety and effectiveness of protriptyline in pediatric patients have not been established. METABOLISM:

Metabolic studies indicate that protriptyline is weil absorbed from the gastrointestinal tract and is rapidly sequestered in issues. Relatively low plasma levels are found after administration, and only a small amount of unchanged drug is excreted in the urine of dogs and rabbits. Preliminary studies indicate that demethylation of the secondary amine moiety ccurs to a significant extent, and that metabolic transformation probably takes place in the liver. It penetrates the brain rapidly in mice and rats, and moreover that which is present in the brain is almost all unchanged drug.

Studies on the disposition of radioactive protriptyline in human test subjects showed significant plasma levels within 2 hours, peaking at 8 to 12 hours, then declining gradually.

Urinary excretion studies in the same subjects showed significant amounts of radioactivity in 2 hours. The rate of excretion was slow. Cumulative urinary excretion during 16 days accounted for approximately $50 \%$ of the drug. The fecal route of excretion did not seem to be important.

Distributed by Odyssey Pharmaceuticals, Inc., East Hanover, New Jersey 07936 Manutactured by PLIVA, Inc., East Hanover, NJ 07936

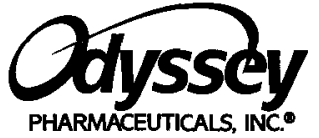

A subsidiary of PLNA*, Inc
72 Eagle Rock Avenue East Hanover, NJ 07936 Tel: $1-877-427-9068$ Fax: $1-877-427-9069$
*Vivactil is a registered trademark of Odyssey Pharmaceuticals, Inc. (C) 2003, Odyssey Pharmaceuticals, Inc. PIOPV-603 04/03 


\section{Get your patients}

\section{with depression}

\section{Into life again}

\section{Vivactil starts working fast to}

improve symptoms of depression ${ }^{1}$

$\checkmark$ Faster than either amitriptyline (reference product, Elavil ${ }^{\circledR *}$ ) or imipramine (reference product, Tofrani ${ }^{\oplus}-\mathrm{PM}^{+}$) in some clinical trials

$\checkmark$ Noticeable improvement of symptoms has occurred in less than 1 week

$\checkmark$ Patients can experience increased energy and activity early in the course of treatment

\section{Vivactil is nonsedating and nontranquilizing ${ }^{1}$}

$\checkmark$ An especially appropriate choice for withdrawn and anergic patients

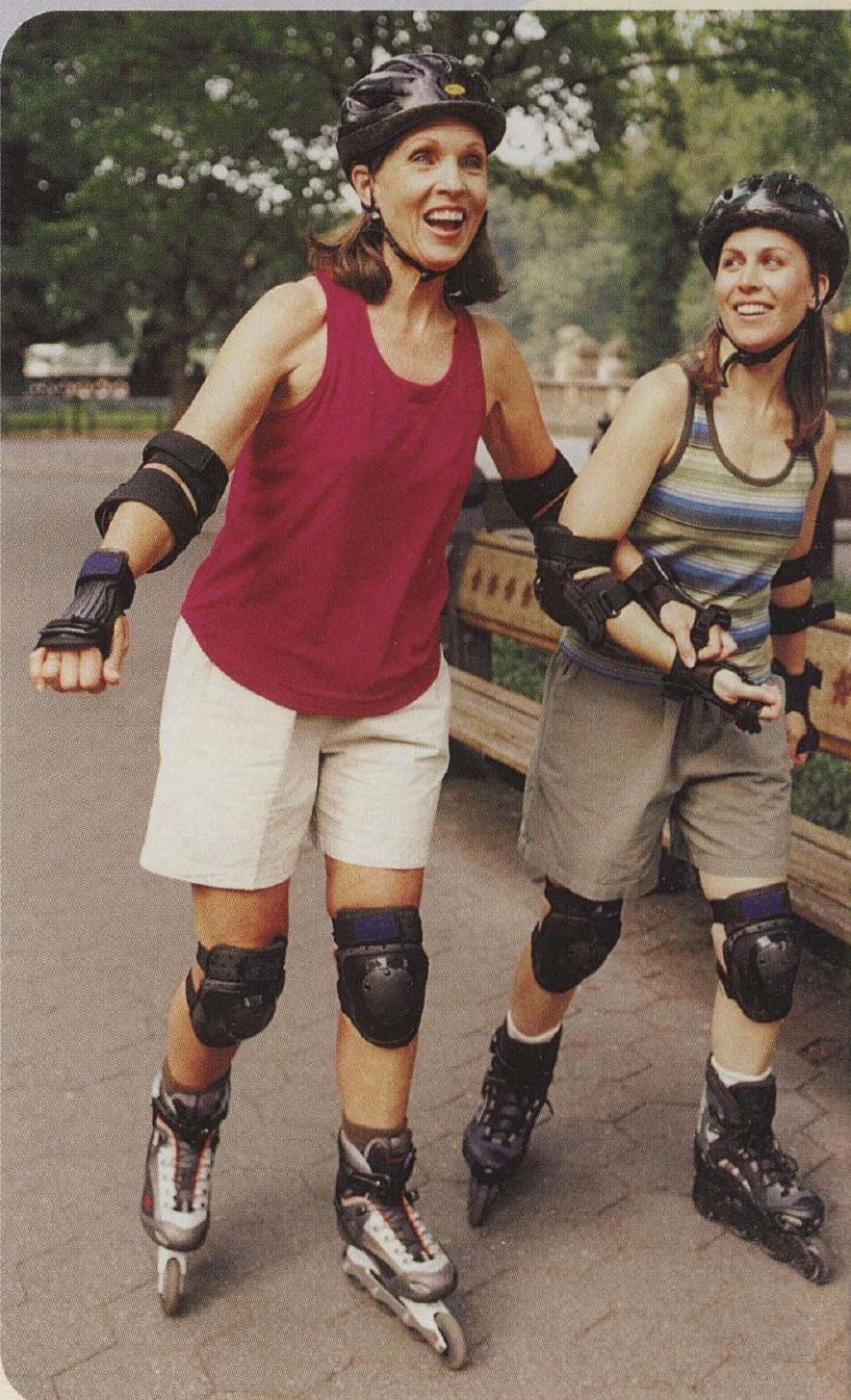

Adverse events associated with TCAs should be considered when prescribing Vivactil. Vivactil may aggravate agitation and anxiety and produce cardiovascular reactions, such as tachycardia and hypotension

Please see brief summary of prescribing information on adjacent page

Exploring the Advantages of Tricyclic Antidepressants an important roundtable discussion featuring leading experts in the treatment of depression - is now available. Ask your Sales Representative for a copy or call Odyssey at 1-877-427-9068.

Visit our website at www.0dysseyPharm.com

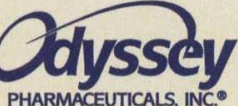

A subsidiary of $P L N A^{\circ}$ Inc.
Help Your Patients With Depression Feel

\section{Vivacious Again}

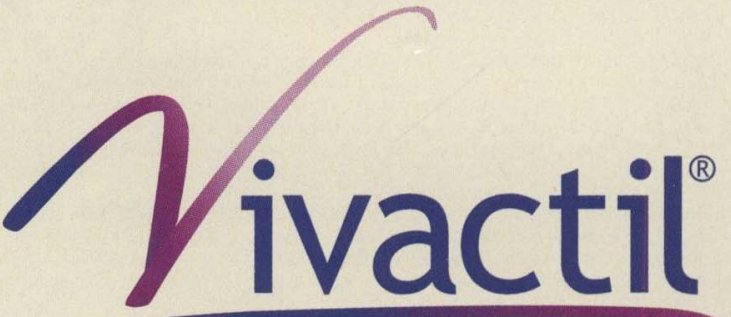

(Protriptyline HCl, USP)

0 P02 $\frac{O P}{701}$ 5-mg and 10-mg Tablets 


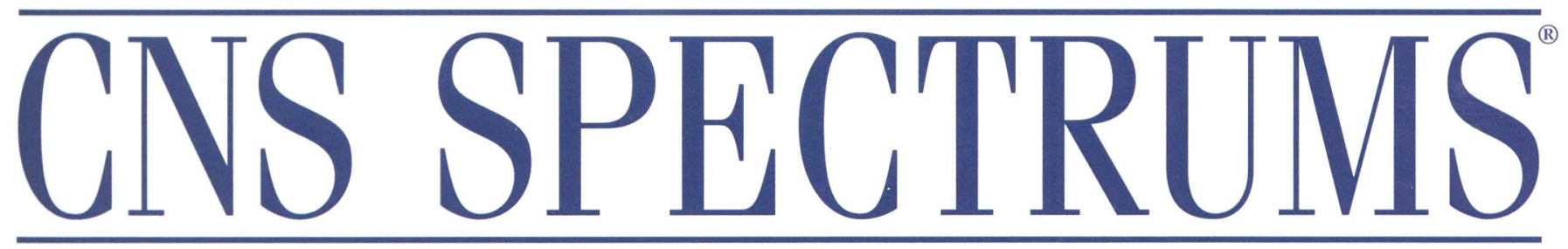

The International Journal of Neuropsychiatric Medicine

\section{Table of Contents}

September 2003

Volume 8 - Number 9

\section{Feature Articles}

\section{INTRODUCTION}

640 The Interdisciplinary Study of Posttraumatic Stress Disorder By Arieh Y. Shalev, MD

\section{REVIEW ARTICLE}

668 Acute Stress Reactions: Can Biological Responses Predict Posttraumatic Stress Disorder?

By Richard A. Bryant, PhD

\section{ORIGINAL RESEARCH}

676 Amnesia for Traumatic Events Among Recent Survivors: A Pilot Study

By Yoram Yovell, MD, PhD, Yair Bannett, and Arieh Y. Shalev, MD

\section{REVIEW ARTICLE}

686 Contemporary Longitudinal Methods for the Study of Trauma and Posttraumatic Stress Disorder By Lynda A. King, PhD, Daniel W. King, PhD, Dawn M. Salgado, MA, and Arieh Y. Shalev, MD

\section{CME-Accredited Articles}

641 Brain-Imaging Studies of Posttraumatic Stress Disorder By Israel Liberzon, MD, and K. Luan Phan, MD

651 The Neuroendocrinology of Posttraumatic Stress Disorder: New Directions

By Ann M. Rasmusson, MD, Meena Vythilingam, MD, and Charles A. Morgan III, MD

693 Genetics of Posttraumatic Stress Disorder

By Ronnen H. Segman, MD, and Arieh Y. Shalev, MD
CNS Spectrums is an

Index Medicus journal and is available on MEDLINE under the citation CNS Spectr.

It is also indexed by DIALOG, EMBASE/Excerpta Medica, OVID, Lexis-Nexis, and SilverPlatter.

CNS Spectrums is the official journal of the International Neuropsychiatric Association with members in 30 countries.

\section{CNS Spectrums ${ }^{\circledast}$}

(ISSN 1092-8529)

is published monthly by

MBL Communications, Inc. 333 Hudson Street, 7th Floor New York, NY 10013

One year subscription rates: domestic \$120; foreign $\$ 185$; in-training $\$ 75$.

For subscriptions:

Fax 212-328-0600

or visit our Web site:

www.cnsspectrums.com

Postmaster:

Send address changes to CNS Spectrums

clo PPS Medical Marketing Group 264 Passaic Avenue

Fairfield, NJ 07004-2595 


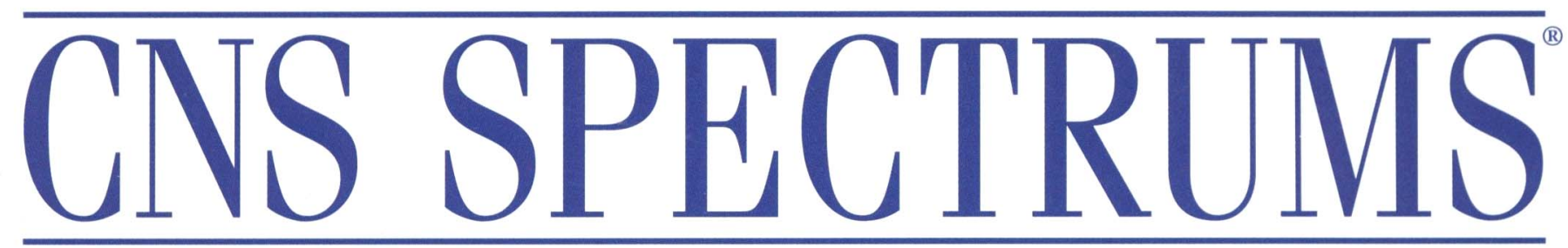

The International Journal of Neuropsychiatric Medicine

\section{Table of Contents}

September 2003

Volume 8 - Number 9

\section{Departments/Monthly Columns}

FROM THE INTERNATIONAL EDITOR'S DESK

634 Posttraumatic Stress Disorder:

\section{A Hidden Epidemic}

By Joseph Zohar, MD

\section{LETTER TO THE EDITOR}

635 Compliments and Critiques From Our Readers

\section{CLINICAL UPDATES IN NEUROPSYCHIATRY}

638 News From the Field of Neuroscience

- Rapid Brain Growth in Infancy May Increase Risk of Autism

- Research Suggests Leukoaraiosis May Precede Stroke

- Food and Drug Administration Approves Levetiracetam Oral for the Treatment of Epilepsy

- Food and Drug Administration Approves Oxcarbazepine for Epilepsy in Children

- Treatment of Depression With Antidepressants May Protect Hippocampal Volume in Women

\section{CONTINUING MEDICAL EDUCATION}

699 This CME quiz on posttraumatic stress disorder is accredited by Mount Sinai School of Medicine for 3.0 credit hours in Category 1.

\section{DIRECTORY OF SERVICES}

702 Editorial Questionnaire

703 Author Guidelines

For editorial inquiries, please fax us at 212-328-0600 or e-mail us at jrr@mblcommunications.com. For advertising inquires, please fax us at 212-328-0600 or e-mail us at: ek@mblcommunications.com kjs@mblcommunications.com.

For bulk reprint purchases, please contact: Kelly J. Staley,

kjs@mblcommunications.com

Opinions and views expressed by authors are their own and do not necessarily reflect the views of the publisher, MBL Communications, Inc., or the editorial advisory board.

Advertisements in CNS Spectrums are accepted on the basis of adherence to ethical medical standards, but acceptance does not imply endorsement by CNS Spectrums or the publisher.

CNS Spectrums ${ }^{\circledR}$ is a registered trademark of CNS Spectrums, LLC, New York, NY.

Permission to reproduce articles in whole or part must be obtained in writing from the publisher.

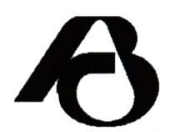

Audit Bureau of Circulations MEM BER SINCE 20001

Copyright $\mathrm{C} 2003$ by MBL

Communications, Inc. All rights reserved. Printed in the United States. 
A different path to success in your continuing treatment of schizophrenia.

\section{Prescribe now}
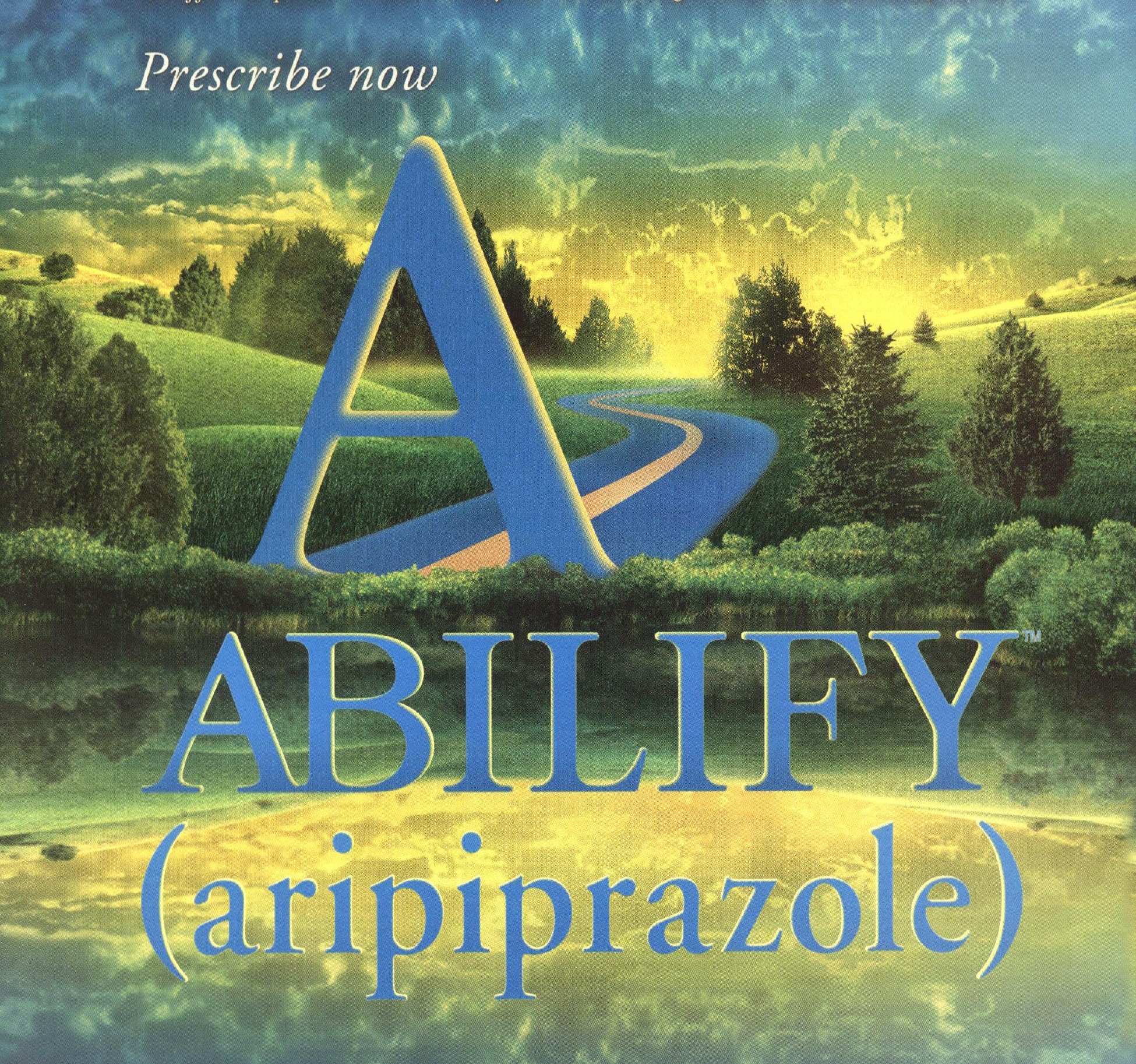

Abilify is indicated for the treatment of schizophrenia.

As with all antipsychotic medications, a rare condition referred to as neuroleptic malignant syndrome (NMS) has been reported. As with all antipsychotic medications, prescribing should be consistent with the need to minimize the risk of tardive dyskinesia (TD). Abilify may be associated with orthostatic hypotension and should be used with caution in patients with known cardiovascular disease, cerebrovascular disease, or conditions which would predispose them to hypotension. Seizures occurred in $0.1 \%$ of Abilify-treated patients in short-term, placebo-controlled trials. As with other antipsychotic drugs, Abilify should be used with caution in patients with a history of seizures or with conditions that lower the seizure threshold.

Treatment-emergent adverse events reported at an incidence of $\geq 10 \%$ and greater than placebo include headache, anxiety, insomnia, nausea, vomiting, lightheadedness, somnolence, akathisia, and constipation.

Please see Brief Summary of Prescribing Information on adjacent page. For more information, visit our web site at www.abilify.com.

Marketed by Otsuka America Pharmaceutical, Inc., Rockville, MD 20850 USA and Bristol-Myers Squibb Co., Princeton, NJ 08543.

Manufactured by Otsuka Pharmaceutical Co., Ltd., Tokyo, 101-8535 Japan. Distributed by Bristol-Myers Squibb Co., Princeton, NJ 08543. U.S. Patent Nos. 4,734,416 and 5,006,528. 


\section{ABILIFY}

\section{(aripiprazole) Tablets}

Bries Summary of Prescribing Information. For complete prescribing information

\section{INDICATIONS AND USAGE}

ABILIFY (aripiprazole) is indicated for the treatment of schizophrenia. The efficacy 6-week) controlled trials of schizophrenic inpatients (see CunicaL PHABMACOLOGY: Clinical Studles). The long-term efficacy of aripiprazole in the treatABILIFY for extended periods should periodically re-evaluate the long-term usethess of the drug for the individual patient.

CONTRAINDICATIONS

product.

Wallonant Syndrome (NMS): A potentially fatal symptom complex sometimes referred to as Neuroleptic Malignant Syndrome (NMS) has been reported in association with administration of antipsychotlc drugs, including the premarketing woridwide clinical database. Clinical manifestations of NMS are hyperpyrexia, muscle rigidity, altered mental status, and evidence of autonomic instability (irregular pulse or blood pressure, tachycardia, diaphoresis, and cardiac dysrhythmia). Additional signs may include elevated creatine phosphokinase, of patients with this syndrome is complicated. In arriving at a diagnosis, it is mportant to exclude cases where the clinical presentation includes both serious
medical illness (e.g., pneumonia, systemic infection, etc) and untreated or inade-
quately treated extrapyramidal signs and symptoms (EPS). Other important conquately treated extrapyramidal signs and symptoms (EPS). Other important conheat stroke, drug fever, and primary central nervous system pathology. The mandrugs and other drugs not essential to concurrent therapy; 2) intensive symptomatic treatment and medical monitoring; and 3) treatment of any concomitant serious medical problems for which specific treatments are avaliable. There is no general agreement about specific pharmacological treatment regimens for uncomplicated NMS. If a patient requires antipsychotic drug treatment atter recovery from NMS, the potential reintroduction of drug therapy should be carefully considered. The patient should be carefolly monitored, since recurrences of
NMS have been reported. Tardive Dyskinesia: A syndrome of potentially irreversible, involuntary, dyskinetic movements may develop in patients treated with antipsychotic drugs. Although the prevalence of the syndrome appears to be highest among the elderly, especially elderly women, it is impossible to rely upon
prevalence estimates to predict, at the inception of antipsychotic treatment, which patients are likely to develop the syndrome. Whether antipsychotic drug products differ in their potential to cause tardive dyskinesia is unknown. The risk of developing tardive dyskinesia and the likelihood that it will become irreversible are
believed to increase as the duration of treatment and the total cumulative dose of believed to increase as the duration of treatment and the total cumulative dose of
antipsychotic drugs administered to the patient increase. However, the syndrome can develop, although much less commonly, after relatively brief treatment peridyskinesia, although the syndrome may remit, partially or completely, if antipsypress (or partially suppress) the signs and symptoms of the syndrome and, thereby, may possibly mask the underlying process. The effect that symptomatic suppression has upon the long-term course of the Syndrome is unknown. Given these
considerations, ABILIFY should be prescribed in a manner that is most likely to minimize the occurrence of tardive dyskinesia. Chronic antipsychotic treatment should generally be reserved for patients who suffer from a chronic illness that (1) effective, but potentielly less harmful treatments are not available or appropriate. In patients who do require chronic treatment, the smallest dose and the shortest duration of treatment producing a satisfactory clinical response should be sought. symptoms of tardive dyskinesia appear in a patient on ABILIFY, drug discontinuation should be considered. However, some patients may require treatment with ABILIFY despite the
PRECAUTIONS

General: Orthostatic Hypotension: Aripiprazole may be associated with orthostatic hypotension, perthaps due to its $\alpha_{1}$-adrenergic receptor antagonism. The incibo-contro:led trials in schizophrenia (n=926) on ABILIFY (aripiprazole) included: orthostatic hypotension (placebo $1 \%$, aripiprazole $1.9 \%$ ); orthostatic lightheaded-
ness (placebo $1 \%$, aripiprazole $0.9 \%$, and syncope iplacebo $1 \%$, aripiprazole ness (placebo $1 \%$, aripiprazole $0.9 \%$, and syncope iplacebo $1 \%$, aripiprazole
$0.6 \%$. The incidence of a significant orthostatic change in blood pressure (defined as a decrease of at least $30 \mathrm{~mm} \mathrm{mg}$ in systolic blood pressure when changing from placebo (14\% among aripiprazole-treated patients and $12 \%$ among placebocarciovascular disease (history of myocardial infarction or ischemic heart disease, heart falure or conduction abnormalities), cerebrovascular disease, or conditions which would predispose patients to hypotension (dehydration, hypovolemia, and (1/926) of aripiprazole-treated patients in short-term, placebo-controlled trials. As with a history of seizures or with conditions that lower the seizure threshold, e.g., prevalent in a population of 65 years or older. Potential for Cognitive and Motor Impairment: In short-term, placebo-controlled trials, somnolence was reported in $11 \%$ of patients on ABILLY compared to $8 \%$ of patients on placebo; somnolence
led to discontinuation in $0.1 \%(1 / 926)$ of patients on $A B \mid L I F Y$ in short-term, placebo-controlled trials. Despite the relatively modest increased incidence of somno-
lence compared to placebo, ABILIFY, like other antipsychotics, may have the lence compared to placebo, ABILIFY, like other antipsychotics, may have the
potential to impair judgment, thinking, or motor skills. Patients should be caupotential to impair judgment, thinking, or motor skills. Patients should be caureasonably certain that therapy with ABILIFY does not affect them adversely. Body
Temperature Regulation: Disruption of the body's ability to reduce core body temTemperature Regulation: Disruption of the body's ability to reduce core body tem-
perature has been attributed to antipsychotic agents. Appropriate care is advised when prescribing aripiprazole for patients who will be experiencing conditions which may contribute to an elevation in core body temperature, e.g. exercising
strenuously, exposure to extreme heat, receiving concomitant medication with strenuously, exposure to extreme heat, receiving concomitant medication with
anticholinergic activity, or being subject to dehydration. Dysphagia: Esophageal dysmotility and aspiration have been associated with antipsychotic drug use. Aspiration pneumonia is a common cause of morbidity and mortality in elderly patients, in particular those with advanced Alzheimer's dementia. Aripiprazole and other antipsychotic drugs should be used cautiously in patients at risk for aspira-
tion pneumonia isee PRECAUTIONS: Use in Patients with Concomitant ithess) Suicide: The possibility of a suicide attempt is inherent in psychotic illnesses, and close supervision of high-risk patients should accompany drug therapy.
Prescriptions tor ABLLIFY should be written tor the smallest quantity of tablets consistent with good patient management in order to reduce the risk of overdose. Use
in Patients with Concomitant lliness: Safety Experience in Eiderly Patients with in Patients with Concomitant Ihress: Safety Experience in Elderly Patients with
Psychosis Associated with Alzheimer's Disease: In a flexible dose (2 to 15 my/day), 10-week, placebo-controlled study of aripiprazole in elderly patients (mean age: 81.5 years; range: 56 to 95 years) with psychosis associated with
Alzheimer's dementia, 4 of 105 patients $(3.8 \%$ ) who received ABILIFY died comAlzheimer's dementia, 4 of 105 patients (3.8\%) who received ABILIFY died com-
pared to no deaths among 102 patients who received placebo during or within 30 pared to no deaths among 102 patients who received placebo during or within 30
days after termination of the double-blind portion of the study. Three of the patients (age 92, 91, and 87 years) died following the discontinuation of ABILIFY
(aripiprazole) in the double-blind phase of the study (causes of death were pneumonia, heart failure, and shock). The fourth patient (age 78 years) died following hip surgery while in the double-bilind portion of the study. The treatmentemergent adverse events that were reported at an incidence of $\geq 5 \%$ and having and bronchitis. Eight percent of the ABLLIFY-treated patients reported somnolence compared to one percent of placebo patients. In a small pilot, open-label, ascend-
ing-dose cohort study (n=30) in elderly patients with dementia, $A B$ LIFY was associated in a dose-related fashion with somnolence. The safety and efficacy of ABILIFY in the treatment of patients with psychosis associated with dementia
have not been established. If the prescriber elects to treat such patients with have not been established, If the prescriber elects to treat such patients with
ABILIFY, vigilance should be exercised, particularly for the emergence of difficulty or aspiration. Clinical experience with ABILIFY in patients with certain concomitan or aspiration. Clinical experience with ABILIFY in patients with certain concomitant impairment and Hepatic impairment ) is limited. ABILIFY has not been evaluated or used to any appreciable extent in patients with a recent history of myocardia infarction or unstable heart disease.

Information for Patients: Physicians are advised to consult full prescribing infor mation to
ABILIFY.

Drug-Dnug Interactions: Given the primary CNS effects of aripiprazole, caution should be used when ABILIFY is taken in combination with other centrally acting drugs and alcohol. Due to its $\alpha_{1}$-adrenergic receptor antagonism, aripiprazole has
the potential to enhance the effect of certain antihypertensive agents. Potential for the potential to enhance the effect of certain antihypertensive agents. Potential for also does not undergo direct glucuronidation. This suggests that an interaction of

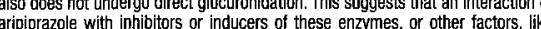
aripiprazole with inhbitors or inducers of these enzymes, or other factors, like
smoking, is unilikely. Both CYP3A4 and CYP2D6 are responsible for aripiprazole metaboilsm. Agents that induce CYP3A4 (e.g., carbamazepine) could cause an

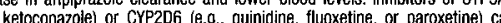
inhibit aripiprazole ellimination and cause increased blood levels. Ketoconazole Coadministration of ketoconazole (200 mg/day for 14 days) with a $15-\mathrm{mg}$ singl
dose of aripiprazole increased the AUC of aripiprazole and its active metabolite by $63 \%$ and $77 \%$, respectively. The effect of a higher ketoconazole dose (400 $\mathrm{mg} / \mathrm{day}$ has not been studied. When concomitant administration of ketoconazole with aripiprazole occurs, aripiprazole dose should be reduced to one-hatf of its normal dose. Other strong inhibitors of CYP3A4 (itraconazole) Would be expected romycin, grapefruit juice) have not been studied. When the CYP3A4 inhibitor

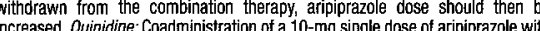
quinidine (166 mg/day for 13 days), a potent intibitor of CYP2D6, increased the UUC of aripiprazole by $112 \%$ but decreased the AUC of its active metabolite, dehydro-aripiprazole, by $35 \%$. Aripiprazole dose should be reduced to one-hall of it normal dose when concomitant administration of quinidine with arlpiprazo occurs. Other significant inhibitors of CYP2D6, such as fluoxetine or paroxetine by similar dose reductions. When the CYP2D6 inhibitor is withdrawn from the combination therapy, aripiprazole dose should then be increased. Carbamazepine: Coadministration of carbamazepine ( $200 \mathrm{mg} \mathrm{BID}$ ), a potent CYP3A4 inducer, with aripiprazole $\left(30 \mathrm{mg} \mathrm{OD}\right.$ ) resulted in an approximate $70 \%$ decrease in $\mathrm{C}_{\text {max }}$ and When carbamazepine is added to aripiprazole therapy, aripiprazole dose should be doubled. Additional dose increases should be based on clinical evaluation. When carbamazepine is withdrawn from the combination therapy, aripiprazole
dose should then be reduced. No clinically significant effect of famotidine valdose should then be reduced. No clinically significant effect of famotidine, valproate, or lithium was seen on the pharmacokinetics of aripiprazole (see CLINI-
CAL PHARMACOLOGY: Drug-Drug Interactions). Potential for ABILFY to Affect Other Drugs: Aripiprazole is unlikely to cause clinically important pharmacokinetic interactions with drugs metabolized by cytochrome P450 enzymes. In in vivo
studies, $10-$ to $30-\mathrm{mg} /$ day doses of aripiprazole had no significant effect on metabolism by CYP2D6 (dextromethorphan), CYP2C9 (warfarin), CYP2C19 (omeprazole, wartarin), and CYP3A4 (dextromethorphan) substrates. Additional mediated metabolism in vitro (see CLINICAL PHARMACOLOGY: Drug-Drug interactions). Alcohol: There was no significant difference between aripiprazole Interactions). Alcohol: There was no significant difference between aripiprazole
coadministered with ethanol and placebo coadministered with ethanol on performance of gross motor skills or stimulus response in healthy subjects. As with most psychoactive medications, patients should be advised to avoid alcohol while taking ABLLIFY. Carcinogenesis,

Pregnancy Category C: There are no adequate and well-controlled studies in pregnant women. It is not known whether aripiprazole can cause fetal harm when administered to a pregnant woman or can affect reproductive capacity. weighs the potential risk to the fetus. Labor and Delivery: The effect of aripiprzole on labor and delivery in humans is unknown. Nursing Mothers: Aripiprazole was excreted in milk of rats during lactation. It is not known whether aripiprazole receiving aripiprazole should not breast-feed. Pediatric Use: Safety and effectiveness in pediatric and adolescent patients have
not been established. Geriatric Use: Of the 5592 patients treated with aripiprazole in premarketing clinical trials, $659(12 \%)$ were $\geq 65$ years old and 525
$(9 \%)$ were $\geq 75$ years old. The majority $(91 \%)$ of the 659 patients were diagnosed with dementia of the Alzheimer's type. Placebo-controlled studies of aripiprazol in schizoptrenia did not include sufficient numbers of subjects aged 65 and over to determine whether they respond differently from younger subjects. There was no effect of age on the pharmacokinetics of a single $15-\mathrm{mg}$ dose of aripiprazole.
Aripiprazole clearance was decreased by $20 \%$ in elderly subjects $(\geq 65$ years Aripiprazole clearance was decreased by $20 \%$ in elderly subjects $(\geq 65$ years
compared to younger adult subjects (18 to 64 years), but there was no detectable effect of age in the population pharmacokinetic analysis in schizophrenia patients. have suggested that there may be a different tolerability profile in this population compared to younger patients with schizophrenia isee PRECAUTIONS: Use Patients with Concomitant illiness). The safety and efficacy of ABILIFY in the treatment of patients with psychosis associated with Alzheimer's disease has not been established. If the prescriber elects to treat such patients with ABILIFY, vigilance should be exercised.

\section{ADVERSE REACTIONS}

Aripiprazole has been evaluated for safety in 5592 patients who participated in of the Alzheimer's type, and who had approximately 3639 patient-years of exposure. Adverse Findings observed in Short-Term, Placebo-Controlled Trials of Patients with Schizophrenia The following findings are based on a pool of five placebo-controlled trials (four 4-week and one 6-week) in which aripiprazole was with Oiscontimuation ranging from 2 to $30 \mathrm{mg}$ /day. Adverse Events Associated Dverall, there was no difference in the incidence of discontinuation due to adverse events between aripiprazole-treated (7\%) and placebo-treated ( $(\%)$ patients. The prazole and placebo-treated patients. Adverse Events occurring at an incidence of $>2 \%$ Among Aripiprazole-Treated Patients and Greater than Placebo in Short Term, Placebo-Controlled Thials: Treatment-emergent adverse events that occurred during acute therapy (up to 6 weeks) at an incidence of $2 \%$ or more of
patients treated with aripiprazole (doses $\geq 2 \mathrm{mg} /$ day) and for which the incidence patients treated with aripiprazole (doses $\geq 2 \mathrm{mg} / \mathrm{day}$ ) and for which the inciden headache, asthenia, and fever; Digestive System - nausea, vomiting, and cons pation; Nervous System-anxiety, insomnia, lightheadedness, somnolence
akathisia, and tremor; Respiratory System-ihinitis and coughing; Skin and
Appendages-rash; Special Senses-blurred vision. Dose-Related Adverse Events. The only adverse event to have a possible dose response relationship, and 8.7\%; 20-mg, 7.5\%;30-mg, 15.3\%). Extrapyramidal Symptoms: In short-term, placebo-controlled trials, the incidence of reported EPS for aripiprazole-treated patients was $6 \%$ vs. $6 \%$ for placebo. Objectively collected data from those trials
on the Simoson Angus Rating Scale (for EPS), the Bames Akathisia Scale (for on the Simpson Angus Rating Scale (for EPS), the Barnes Akathisia Scale (for akathisia), and the Assessments of involuntary Movement Scales (tor dyskinesias) also did not show a difference between aripiprazole and placebo, with the excep-
tion of the Barnes Akathisia Scale (aripiprazole, 0.08 ; placebo, -0.05 ). Laboratory Test Abnormalities: A between group comparison for 4- to 6 -week placebo-conand placebo groups in the proportions of patients experiencing potentially clinically significant changes in routine serum chemistry, hematology, or urinalysis parameters. Weight Gain: In short-term trials, there was a slight difference in mean weight gain between aripiprazole and placebo patients $(+0.7 \mathrm{~kg}$ vs. -0.0 $\mathrm{kg}$, respectively), and also a difference in the proportion of patients meeting
weight gain criterion of $\geq 7 \%$ of body weight [aripiprazole (8\%) compared to placebo (3\%)]. ECG Changes: Between group comparisons for pooled placebocontrolled trials revealed no significant differences between aripiprazole and in ECG parameters; within the oose range of 10 to $30 \mathrm{mg} / \mathrm{day}$, aripiprazole tended to slightly shorten the OTc interval. Aripiprazole was associated with a median
increase in heart rate of 4 beats per minute compared to a 1 beat per minute
increase among placebo patients. Other Adverse Events Observed During Clinical increase among placebo patients. Other Adverse Events Observed During Clinical
Trials: Following is a list of modified COSTART terms that reflect treatment-emergent adverse events reported by patients treated with aripiprazole at multiple doses $\geq 2 \mathrm{mg} / \mathrm{day}$ during any phase of a trial within the database of 5592 patients It is important to emphasize that, although the events reported occurred during
treatment with aripiprazole, they were not necessarily caused by it. Frequent treatment with aripiprazole, they were not necessarily caused by it. Frequent 1/1000 patients; rare events in fewer than 1/1000 patients. Body as a Whole: Frequent - flu syndrome, peripheral edema, chest pain, neck pain, neck rigidity
infrequent - pelvic pain, suiciơe attempt, face edema, malaise, photosensitivity arm rigioity, jaw pain, chills, bloating, jaw tightness, enlarged abdomen, chest tightness; Rare - throat pain, back tigntness, head heaviness, moniliasis, throat
bightness, leg rigidity, neck tightness. Mendelson's syndrome, heat stroke tightness, leg rigidity, neck tightness, Mendelson's syndrome, heat stroke
Cardiovascular System: Frequent - hypertension, tachycardia, hypotension bradycardia; Infrequent - palpitation, hemorrhage, myocardial infarction, promyocardial ischemia, phlebitis, deep vein thrombosis, angina pectoris, extrasystoles; Rare - vasovagal reaction, cardiomegaly, atrial flutter, thrombophlebitis. Digestive System: Frequent - anorexia, nausea and vomiting; Infrequent gingivitis, hemorrhoids, gastroesophageal reflux, gastrointestinal hemorrhage, periodontal abscess, tongue edema, fecal incontinence, colitis, rectal hemorrhage, stomatitis, mouth ulcer, cholecystitis, fecal impaction, oral momiliasis,
cholelithiasis, enuctation, intestinal obstruction, peptic ulcer; Rare - esophagitis gum hemorrhage, glossitis, hematemesis, melena, duodenal ulcer, cheilitis, hepatitis, hepatomegaly, pancreatitis, intestinal perforation. Endocrine System System: Frequent - ecchymosis, anemia; infrequent - hypochromic anemia eosinophilia, thrombocythemia, macroctic anemia. Metabolic and Nutritiona Disorders: Frequent - weight loss, creatine phosphokinase increased; infrequent - dehydration, edema, hypercholesteremia, hyperglycemia, hypokalemia, dia( deficiency anemia, creatinine increased, bilirubinemia, lactic dehydrogenase increased, obesity; Rare - hyperkalemia, gout, hypernatremia, cyanosis, hypercramp, Infrequent - arthralgia, bone pain, myastheria, arthritis, arthrosis, musclie weakness, spasm, bursitis; Rare - rhabdomyolysis, tendonitis, tenosynovitis, heumatoid arthritis, myopathy. Nervous System: Frequent - depression, abnornal gait, confusion, cogwheel rigidity; Infrequent - dystonia, twitch, impaired concentration, paresthesia, vasodilation, hypesthesia, extremity tremo impotence, bradykinesia, decreased libido, panic attack, apathy, dyskinesia,
hypersomnia, vertigo, dysarthria, tardive dyskinesia, ataxia, impaired memory, hypersomnia, vertigo, dysarthria, tardive dyskinesia, ataxia, impaired memory,

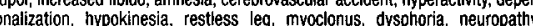
ncreased reflexes, slowed thinking, hyperkinesia, hyperesthesia, hypotonia, oculogyric crisis; Rare - delirium, euphoria, buccoglossal syndrome, akinesia, bluntreflexes, obsessive thought, intracranial hemorrhage. Respiratory System: Frequent - dyspnea, pneumonia; Infrequent - asthma, epistaxis, hiccup, laryng-
ts; Rare - hemoptysis, aspiration pneumonia, increased sputum, dry nasal sages, pulmonary edema, pulmonary embolism, hypoxia, respiratory failure, apnea. Skin and Appendages: Frequent - dry skin, pruritus, sweating, skin ulcer Infrequent - acne, vesiculobullous rash, eczema, alopecia, psoriasis, seborrhea; Frequent - conjunctivitis, ear pain; Infrequent - dry eye, eye pain, tirnitus, otitis media, cataract, altered taste, blepharitis; Rare - increased lacrimation, frequent blinking, otitis externa, amblyopia, deafness, diplopia, eye hemorrhage, photo-
phobia. Urogenital System: Frequent - urinary incontinence; Infrequent-cystitis, urinary frequency, leukorrhea, urinary retention, hematuria, dysuria, amenorntea, abnormal ejaculation, vaginal hemorrhage, vaginal moniliasis, kidney failure, uterus hemorrhage, menorrhagia, albuminuria, kidney calculus, nocturia, polyuria, urinary urgency; Rare - breast pain, cervicitis, female lactation,
nary burning, glycosuria, gynecomastia, urolithiasis, priapism.

\section{OVERDOSAGE}

Management of Overdosage: No specific information is available on the treat ment of overdose with aripiprazole. An electrocardiogram should be obtained in case of overdosage and, if QTc interval proiongation is present, cardiac monitor-
ing should be insituted. Otherwise, management of overdose should concentrate on supportive therapy, maintaining an adequate airway, oxygenation and ventilalon, and management of symptoms. Close medical supervision and monitoring of ABILIFY, an early charcoal administration may be useful in partially preventing the absorption of aripiprazole. Administration of $50 \mathrm{~g}$ of activated charcoal, one $C_{\max }$ of aripiprazole by $50 \%$

DRUG ABUSE AND DEPENDENCE

Controlled Substance: ABILIFY (aripiprazole) is not a controlled substance.

Abuse and Dependence: Aripiprazole has not been systematically studied in Abuse and Dependence: Aripiprazole has not been systematically studied in
humans for its potential for abuse, tolerance, or physical dependence. In physical dependence studies in monkeys, withdrawal symptoms were observed upon abrupt cessation of dosing. While the clinical trials did not reveal any tendency for possible to predict on the basis of this limited experience the extent to which a CNS-active drug will be misused, diverted, and/or abused once marketed. Consequently, patients should be evaluated carefully for a history of drug abuse, (e.g. development of tolerance, increases in dose, drug-seeking behavior). and Bristol-Myers Squibb Co., Princeton, NJ 08543 USA.

Manufactured by Otsuka Pharmaceutical Co., Ltd., Tokyo, 101-8535 Japan.

Distributed by Bristol-Myers Squibb Co., Princeton, NJ 08543 USA.

Bristoi-Myers Squibb Compan

D6-B001A-11-02 A4115/10-02

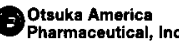

2003 Otsuka Pharmaceutical Co., Ltd., Tokyo, 101-8535 Japan. 


\section{THE INTERNATIONAL JOURNAL OF \\ NeUROPSYCHiATRIC MEDiCINE...ONLINE}

CNS Spectrums" available FREE Online!

Instant certification upon quiz completion

Simple registration allows easy access to CME sections

\section{0 hours of FREE CME} credit currently available

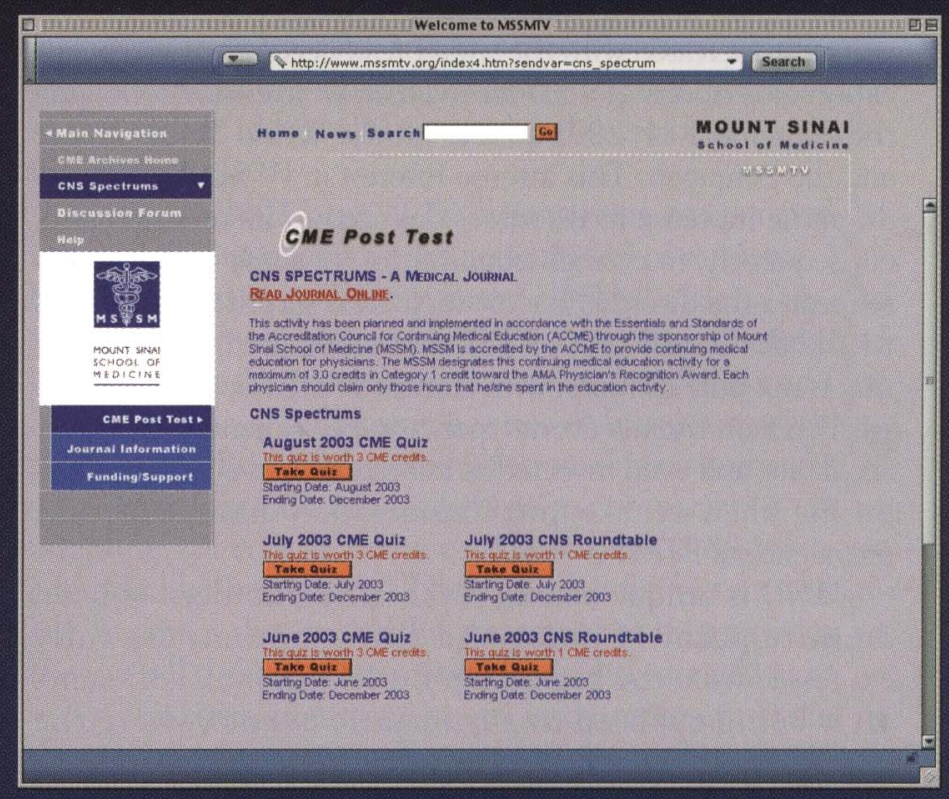

"The International Journal of Neuropsychiatric Medicine" www.cnsspectrums.com

Bipolar Disorder Roundtable Monograph Series An Expert Panel Review of Clinical Challenges in Primary Care and Psychiatry

Earn up to 3 hours of free CME credit by accessing the following expert panel discussions now available online at: www.cnsspectrums.com

Part 1: Recognizing Comorbidities Associated With Bipolar Disorder Moderator: Robert M. A. Hirschfeld, MD Discussants: Allan H. Young, MB, ChB, and Susan McElroy, MD

Part 2: Remission-Oriented Treatment Considerations in Bipolar Disorder Moderator: Robert M. A. Hirschfeld, MD

Discussants: Michael Gitlin, MD, and Mark Hyman Rapaport, MD

Part 3: Optimizing Therapeutic Options in the Treatment of Bipolar Disorder Moderator: Robert M. A. Hirschfeld, MD

Discussants: David V. Sheehan, MD, MBA, and Martin B. Keller, MD 